\title{
Characterisation of a glycine to valine substitution at amino acid position 910 of the triple helical region of type III collagen in a patient with Ehlers-Danlos syndrome type IV
}

\author{
A J Richards, J C Lloyd, P N Ward, A De Paepe, P Narcisi, F M Pope
}

\begin{abstract}
We have studied a patient with Ehlers-Danlos syndrome type IV. Protein mapping studies of her type III collagen had indicated that cyanogen bromide fragment 9 contained the site of the mutation. Here we describe the mapping of this region for a single base mutation using a chemical modification and cleavage technique. Sequence analysis of cDNA showed a $G$ to $T$ mutation resulting in the substitution of glycine 910 by valine. This was confirmed by allele specific oligonucleotide hybridisation to the proband's genomic DNA.
\end{abstract}

Ehlers-Danlos syndrome (EDS) is a group of diseases characterised by joint laxity and variable abnormalities of the skin and other connective tissues. ${ }^{12}$ The most severe of these is EDS IV (acrogeric type), which is usually inherited in an autosomal dominant fashion. Affected subjects typically have thin, fragile skin with easily visible veins and prematurely aged hands and feet. They also have the life threatening tendency to rupture arterial vessels and hollow organs. Previous studies have shown that fibroblasts from EDS IV patients secrete a decreased level of type III collagen. ${ }^{3-5}$ Indeed RFLP analysis using type III collagen cDNA probes has shown the disease to be linked to the type III collagen gene, COL3A1. ${ }^{6}$

More recently a number of mutations of COL3A1 have been described in EDS IV patients; these

Dermatology Research Group, Clinical Research Centre, Northwick Park Hospital, Harrow, Middlesex HA1 3UJ. A J Richards, J C Lloyd, P Narcisi, F M Pope

Institute for Animal Health, Compton, Berks RG16 0NN. P N Ward

Centre for Medical Genetics, University of Gent, B-9000 Gent, Belgium.

A de Paepe

Correspondence to Dr Richards.

Received for publication 8 November 1990

Accepted for publication 21 December 1990. include large deletions, ${ }^{8-10}$ faulty splicing of RNA, ${ }^{11} 12$ and single base mutations. ${ }^{13} 14$ Both single base mutations have caused the substitution of a glycine residue in the triple helical domain of the molecule. In this region it is a prerequisite for normal assembly of the collagen helix that glycine occurs at every third amino acid. ${ }^{15}$ Many similar glycine substitutions, which cause osteogenesis imperfecta (OI), have now been described in the genes coding for type I collagen, ${ }^{16}{ }^{17}$ and transgenic mice with lethal OI have been produced using a glycine to cysteine/arginine substitution in the mouse COL1A1 gene. ${ }^{18}$ The substitution of glycine by bulkier amino acids within the helical region of collagen is thought to delay the formation of the triple helix and so extend the hydroxylation and glycosylation of lysine residues. This leads to overmodification of the molecule amino terminal to the site of the mutation. ${ }^{19}{ }^{20}$ This in turn leads to poor secretion and retention of the collagen within the cell.

Here we describe a type III collagen mutation in a 55 year old woman who presented with EDS IV. She had short stature, large eyes, a pinched nose, thin lips, lobeless ears, thin skin with bruising, cavus deformity of the feet, and variable joint laxity. Notable previous problems included exaggerated bruising and haematomas, several shoulder dislocations, and a perforated sigmoid volvulus which required surgical resection. She was the only affected member of a family of seven sibs and had no children.

Protein mapping studies on her type III collagen showed that the most carboxy terminal cyanogen bromide fragment (CB9) of the $\alpha$ chains was overmodified. ${ }^{21}$ Consequently, cDNA coding for this region was amplified and mapped for single base mutations. The cDNA was sequenced and a mutation found which converted glycine 910 to valine by changing the codon GGT to GTT.

Materials and methods

RNA ISOLATION AND CDNA SYNTHESIS

Total cytoplasmic RNA was isolated from dermal skin fibroblasts by lysing the cells with $0.5 \%$ NP40 
CB peptides
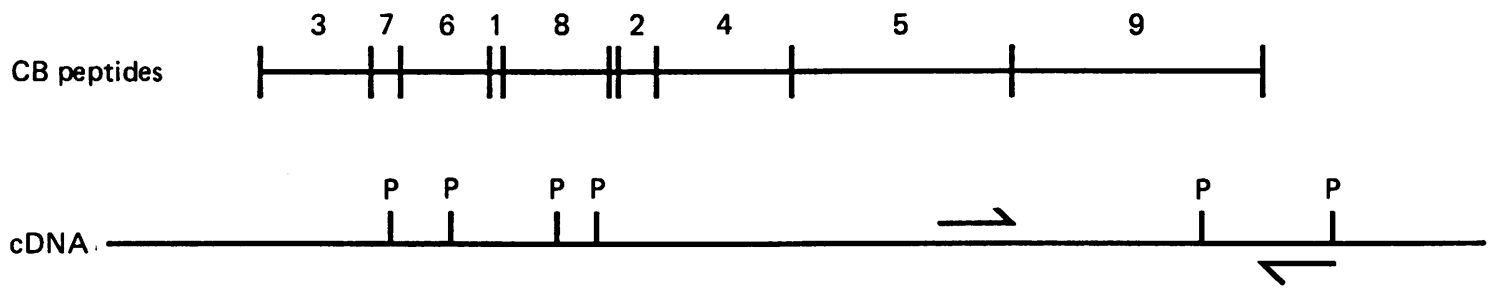

Figure 1 Schematic representation of $C B$ peptides of type III collagen and encoding CDNA. PstI restriction sites are indicated by $P$. The position of the oligonucleotides $C B 93$ and $C B 95$ are indicated by the arrows.

containing vanadyl ribonucleoside complexes. After the removal of nuclei, the crude RNA preparation was digested with proteinase $K$, phenol:chloroform extracted, and finally ethanol precipitated. ${ }^{22}$ This total RNA was used for first strand synthesis of cDNA. The RNA ( $5 \mu \mathrm{g}$ ) was annealed to $10 \mathrm{pmol}$ of the antisense oligonucleotide CB93 (see below) at $65^{\circ} \mathrm{C}$ for five minutes with 20 units of human placental ribonuclease inhibitor (BRL) in a volume of $8 \mu \mathrm{l}$. After annealing, reverse transcription was performed at $42^{\circ} \mathrm{C}$ for one hour in $50 \mathrm{mmol} / \mathrm{l}$ Tris$\mathrm{HCl}, \mathrm{pH} 8.3,50 \mathrm{mmol} / 1 \mathrm{KCl}, 10 \mathrm{mmol} / 1 \mathrm{MgCl}_{2}$, $1 \mathrm{mmol} / 1 \mathrm{DTT}, 1 \mathrm{mmol} / \mathrm{l} \mathrm{EDTA}, 10 \mu \mathrm{g} / \mathrm{ml} \mathrm{BSA}$, $1 \mathrm{mmol} / \mathrm{l}$ of each $\mathrm{dNTP}, 4 \mathrm{mmol} / \mathrm{l}$ sodium pyrophosphate, using 18 units of AMV reverse transcriptase in a total volume of $25 \mu \mathrm{l}$. After incubation the sample was phenol:chloroform extracted and ethanol precipitated. The cDNA was then dissolved. in $15 \mu \mathrm{l}$ of water.

\section{CDNA AMPLIFICATION}

The cDNA sequence coding for CB9 (fig 1) was amplified by the polymerase chain reaction (PCR) ${ }^{23}$ using 2.5 units of Taq DNA polymerase (Perkin Elmer (etus), 2 to $5 \mu \mathrm{l}$ of first strand cDNA, and 50 pmol of the oligonucleotide primers $\mathrm{CB} 93$ and $\mathrm{CB} 95$ (see below) in $10 \mathrm{mmol} / \mathrm{l}$ Tris- $\mathrm{HCl}, \mathrm{pH} 8.4,2.5$ $\mathrm{mmol} / \mathrm{l} \mathrm{MgCl}, 50 \mathrm{mmol} / 1 \mathrm{KCl}$, and $200 \mu \mathrm{mol} / \mathrm{l}$ of each dNTP in a volume of $0.1 \mathrm{ml}$. After an initial denaturation at $95^{\circ} \mathrm{C}$ for five minutes, amplification was achieved through 35 cycles each consisting of denaturation at $95^{\circ} \mathrm{C}$ for 1.5 minutes, annealing at $55^{\circ} \mathrm{C}$ for 1.5 minutes, and elongation at $72^{\circ} \mathrm{C}$ for three minutes. After amplification, the PCR product was ethanol precipitated and purified by electroelution from a $1 \%$.agarose gel and ethanol precipitation of the cDNA.

The primers CB93 (5'GGGGAATTCGGCAGCGGCTCCAACACCACCACA3'-antisense) and CB95 (5'GGGGAATTCGGAGCACGGGGTCTTGCAGGACCA3'-sense) corresponded to nucleotides 3641 to 3714 and 2962 to 2985 respectively of the complete cDNA sequence of type III collagen (HSCOL3AI) in the EMBL DNA sequence database. ${ }^{24}{ }^{25}$ In addition to the 24 coding nucleotides, each primer contained an additional nine nucleotides at their $5^{\prime}$ ends which incorporated $E c o R I$ restriction endonuclease sites into each end of the PCR product.

\section{CHEMICAL CLEAVAGE MAPPING}

Wild type cDNA was amplified from the clone $\mathrm{E}^{26}$ using the primers $\mathrm{CB} 93$ and $\mathrm{CB} 95$. After purification from an agarose gel, the cDNA was digested with the endonuclease $E c o$ RI. The sticky ends created were repaired using the Klenow fragment of DNA polymerase I and $\alpha^{32} \mathrm{P}-\mathrm{dATP}$. The labelled probe was mixed with a 10 to 20 fold molar excess of cDNA, amplified from the proband, using the same oligonucleotide primers. The mixture was boiled for five minutes and then annealed in $0.1 \mathrm{~mol} / 1$ Tris- $\mathrm{HCl}$, $\mathrm{pH} 8,0.3 \mathrm{~mol} / 1 \mathrm{NaCl}$, at $65^{\circ} \mathrm{C}$ for three to 16 hours. Modification of the duplexes was essentially the same as in Roberts et al ${ }^{27}$ except that yeast tRNA was used as a carrier instead of mussel glycogen.

SUBCLONING AND SEQUENCING

Gel purified PCR products were treated with T4 polynucleotide kinase $\mathrm{e}^{22}$ and blunt end ligated into M13mp18. Alternatively, the PCR products were restricted with the endonuclease $H$ infl and the 5' overhangs were repaired with Klenow and dNTPs ${ }^{22}$ before treatment with kinase and ligation into M13mp18. M13 subclones were sequenced with sequenase (United States Biochemical Corp) using conditions specified by the manufacturer and either an M13 primer or an internal 17 nucleotide primer corresponding to normal type III collagen cDNA sequence.

\section{ALLELE SPECIFIC OLIGONUCLEOTIDE (ASO)}

HYBRIDISATION

DNA was isolated from either dermal skin fibroblasts or lymphocytes as described previously. ${ }^{7}$ The oligonucleotides A5 (5' TGGAAAGAGTGGTGACAGAGGAGA 3') and B3 (5' TTTGTCACCACGTGGGCCTTGAGG $3^{\prime}$ ) were used to amplify a region of the 
COL3A1 gene which contained the suspected site of the mutation. Genomic DNA ( $1 \mu \mathrm{g})$ was amplified using the same conditions as for cDNA, but was achieved using 10 cycles consisting of $95^{\circ} \mathrm{C}$ for 2.5 minutes, $65^{\circ} \mathrm{C}$ for two minutes, and $72^{\circ} \mathrm{C}$ for five minutes, followed by 40 cycles consisting of $95^{\circ} \mathrm{C}$ for 1.5 minutes, $65^{\circ} \mathrm{C}$ for 1.5 minutes, and $72^{\circ} \mathrm{C}$ for four minutes. After amplification, small aliquots of the PCR products were electrophoresed in $1 \%$ agarose gels and Southern blotted. ${ }^{28}$ The allele specific oligonucleotides ASOG (5' GCTCCCGGTCCTGCT $3^{\prime}$ ) and ASOT (5' GCTCCCGTTCCTGCT 3') were labelled with T4 polynucleotide kinase and $\gamma^{32}$ P-ATP and used to probe the Southern blots. The filters were then washed in tetramethylammonium chloride using the conditions described by Wood et al. ${ }^{29}$ Signals were detected by autoradiography at $-70^{\circ} \mathrm{C}$.

\section{Results}

CHEMICAL CLEAVAGE MAPPING

Analysis of type III collagen from the proband indicated that the CB9 region of the protein was overmodified, and that the mutation was likely to be present within this region of the molecule. ${ }^{21}$

cDNA encoding this region was therefore mapped using the chemical cleavage technique for detecting single base mutations, ${ }^{27}{ }^{30}$ using hydroxylamine as the modifying agent. This approach is particularly useful for detecting mutations which lead to substitution of glycine residues (coded for by GGN) since they lead to mismatches of cytosines in the antisense strand of a labelled wild type probe. It is these mismatched cytosines which are modified and subsequently cleaved during the mapping procedure.

Thus wild type cDNA (clone E6) was amplified using the primers $\mathrm{CB} 93$ and $\mathrm{CB} 95$, and the $771 \mathrm{bp}$ product digested with the endonuclease EcoRI. The cDNA was end labelled and hybridised to either cDNA amplified from the proband or to cDNA with a Gly883 to Asp mutation, ${ }^{14}$ using the same oligonucleotides used for synthesis of the probe. These heteroduplexes were then subjected to chemical cleavage mapping, and the products electrophoresed in a denaturing polyacrylamide gel (fig 2). Comparison of the bands produced from the control and proband with standard DNA markers showed that the control cDNA produced a cleaved product of approximately $287 \mathrm{bp}$. This agreed well with the expected size of 294 bp. Mapping of the proband's cDNA showed a cleaved product of approximately $383 \mathrm{bp}$. This therefore corresponded to a mismatched cytosine this distance from one end of the amplified product. The mutation would occur at base position 3340 if the mismatch was in the antisense strand, as expected for a glycine substitution, or at base 3336 if it occurred in the sense strand of the labelled probe.

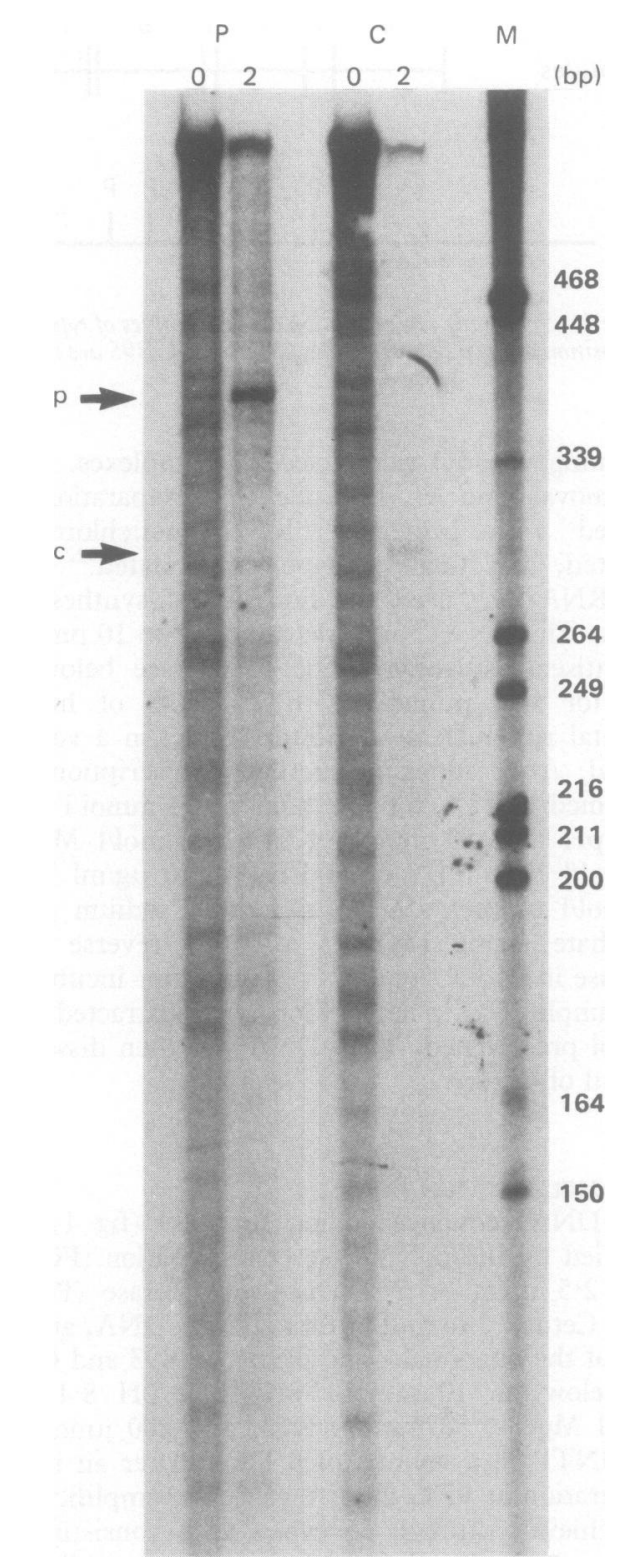

Figure 2 Chemical cleavage mapping of the proband's cDNA. $c D N A$ covering the $C B 9$ region was amplified from the proband $(P)$ and a gly883-asp mutant control $(C)$. These were annealed to labelled wild type probe and left unmodified $(0)$ or modified with hydroxylamine for two hours (2). After cleavage, the cDNAs were electrophoresed in a denaturing polyacrylamide gel along with standard PstI digested $\lambda$ DNA as markers $(M)$.

\section{SEQUENCE ANALYSIS}

The cDNA coding for CB9 was cloned into M13 either as the whole $771 \mathrm{bp} \mathrm{PCR} \mathrm{product} \mathrm{or} \mathrm{as} 482$ and 292 bp fragments after restriction with Hinfl. Analysis of sequences obtained from individual subclones showed a $\mathrm{G}$ to $\mathrm{T}$ mutation at base 3332 (fig 3). 


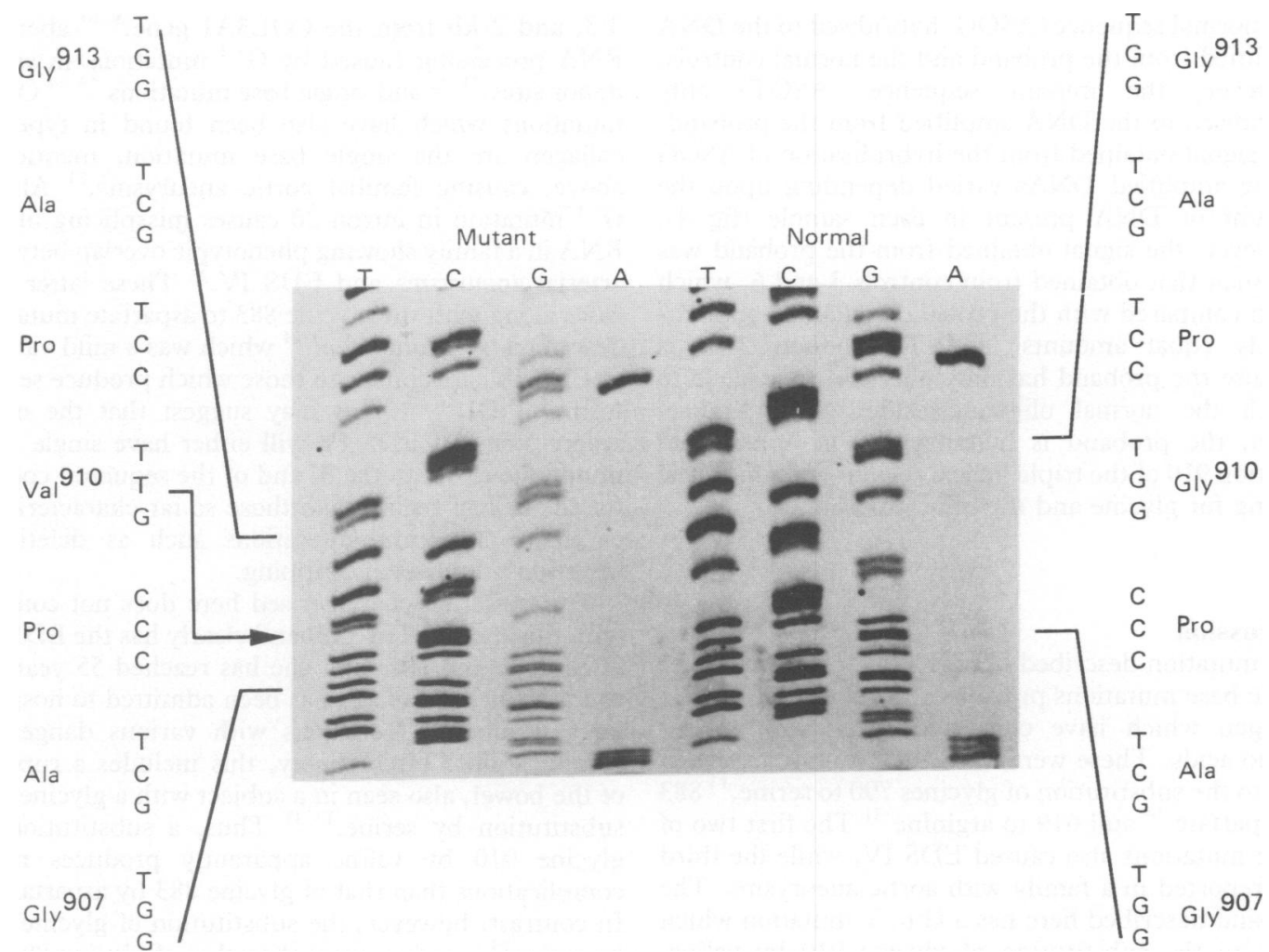

Figure 3 Sequence of mutant and wild type cDNA isolated from the proband. The arrow indicates the position of the single base mutation which converts the codon of GGT for glycine 910 to GTT, a codon for valine.

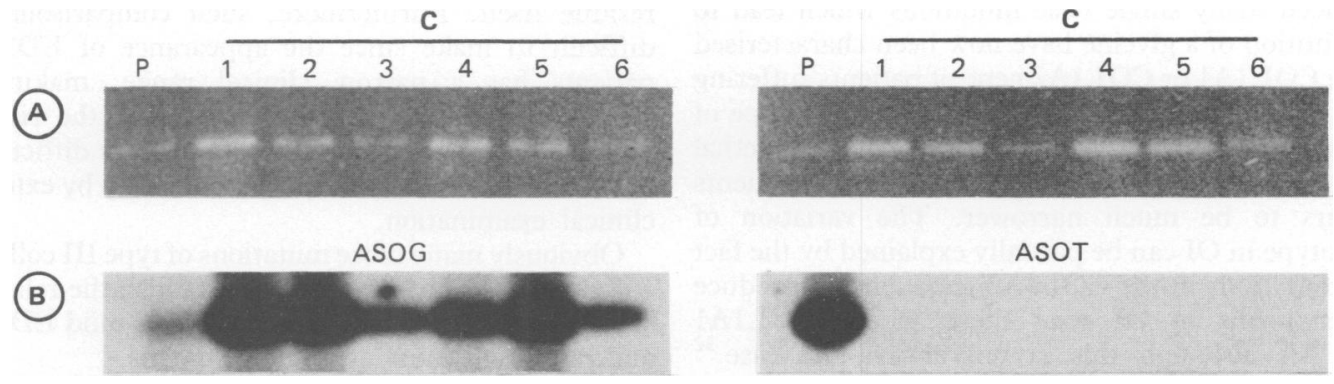

Figure 4 Allele specific oligonucleotide hybridisation. Duplicate agarose gels $(A)$ containing amplified genomic DNA from the proband $(P)$ and normal controls $(C 1-6)$ were Southern blotted and hybridised to oligonucleotides (B) coding for either glycine 910 (ASOG) or valine 910 (ASOT).

This results in a glycine to valine substitution at amino acid position 910 of the triple helical domain, and agrees well with the localisation of the mutation by chemical cleavage analysis, which estimated the site of the mutation to be at base 3340. A total of five mutant clones was found. This was the only base change consistently found in more than one clone. Other base changes detected occurred only in single clones and were deemed to be artefacts created during amplification.
ASO HYBRIDISATIONS

To ensure that the $G$ to $T$ mutation at base 3332 was not the anomalous result of an error during reverse transcription or amplification, hybridisation using allele specific oligonucleotides was performed. Genomic DNA from the proband and normal controls was amplified across the area of the mutation and duplicate aliquots Southern blotted (fig 4A). These were then probed with ASOs which either coded for the normal sequence or the mutant sequence (fig 4B). 
The normal sequence (ASOG) hybridised to the DNA amplified from the proband and the normal controls. However, the mutant sequence (ASOT) only hybridised to the DNA amplified from the proband. The signal obtained from the hybridisation of ASOG to the amplified DNAs varied depending upon the amount of DNA present in each sample (fig 4). However, the signal obtained from the proband was less than that obtained from controls 3 and 6 , which when compared with the proband contained approximately equal amounts of PCR product. This is because the proband has only one wild type allele to which the normal oligonucleotide will hybridise. Thus, the proband is heterozygous at amino acid position 910 of the triple helical region, with one alleke coding for glycine and the other for valine.

\section{Discussion}

The mutation described here is similar to three other single base mutations previously described in type III collagen which have converted glycine to bulkier amino acids. These were all $\mathrm{G}$ to $\mathrm{A}$ mutations which lead to the substitution of glycines 790 to serine, ${ }^{13} 883$ to aspartate ${ }^{14}$ and 619 to arginine. ${ }^{31}$ The first two of these mutations also caused EDS IV, while the third was reported in a family with aortic aneurysms. The proband described here has a $\mathrm{G}$ to $\mathrm{T}$ mutation which leads to the substitution of glycine. 910 by valine. Similar changes cause lethal OI when occurring at glycine residues 256973 , or 1006, in the $\alpha \mathrm{l}$ (I) chain of type I collagen. ${ }^{17} 32$

Indeed many single base mutations which lead to substitution of a glycine have now been characterised in the COL1A1 or COL1A2 gene of patients suffering from OI. ${ }^{16}{ }^{17}$ Interestingly, the clinical phenotype of $\mathrm{OI}$ is wide, ranging from mild to perinatal lethal forms ${ }^{33}{ }^{34}$ while the phenotype of EDS IV patients appears to be much narrower. The variation of phenotype in OI can be partially explained by the fact that mutations in the COL1A2 gene tend to produce milder forms of OI than those in the COL1A1 gene, ${ }^{16} 17$ although this is not always the case. ${ }^{32}$ However, the OI phenotype produced may also depend upon the position of the substituted glycine in the collagen chain. ${ }^{16}{ }^{17}$ Generally, the closer that the substitution is to the carboxy terminal end of the collagen helix the more severe the effect. Which amino acid substitutes for glycine may also affect the phenotypic outcome of the disease. For example, serine and cysteine substitutions are most severe at the carboxy end of the helix of $\alpha \mathrm{l}(\mathrm{I})$ collagen, whereas valine and arginine can be severe even towards the amino end of the helix.

So far it is unclear whether the same general rule can be applied to type III collagen mutations. In EDS IV patients these have included large deletions of $7 \cdot 5$,
$3 \cdot 3$, and $2 \mathrm{~kb}$ from the COL3Al gene, ${ }^{8-10}$ aberrant RNA processing caused by $\mathrm{G}^{+1}$ mutations in splice donor sites, ${ }^{11} 12$ and single base mutations. ${ }^{13}{ }^{14}$ Other mutations which have also been found in type III collagen are the single base mutation, mentioned above, causing familial aortic aneurysms. ${ }^{31}$ Also a $\mathrm{G}^{+1}$ mutation in intron 20 causes missplicing of the RNA in a family showing phenotypic overlap between arterial aneurysms and EDS IV. ${ }^{35}$ These latter two cases along with the glycine 883 to aspartate mutation described by Tromp et al, ${ }^{14}$ which was a mild variant of EDS IV, are similar to those which produce severe forms of OI. ${ }^{16}{ }^{17}$ This may suggest that the more severe forms of EDS IV will either have single base mutations closer to the $3^{\prime}$ end of the sequence coding for the helical region than those so far characterised, or major structural alterations such as deletions, insertions, and exon skipping.

The mutation characterised here does not conflict with this theory. The proband clearly has the EDS IV phenotype and although she has reached 55 years of age without fatality she has been admitted to hospital on a number of occasions with various dangerous complications. Interestingly, this includes a rupture of the bowel, also seen in a subject with a glycine $\mathbf{7 9 0}$ substitution by serine. ${ }^{13} 35$ Thus, a substitution of glycine 910 by valine apparently produces more complications than that of glycine 883 by aspartate. ${ }^{14}$ In contrast, however, the substitution of glycine $\mathbf{7 9 0}$ by serine ${ }^{13}$ is more severe than that of glycine 883 by aspartate ${ }^{14}$ even though it occurs amino terminal to glycine 883. Again it is unclear whether this is a positional effect or the result of the substituting residue itself. Furthermore, such comparisons are difficult to make since the appearance of EDS IV patients has a narrow clinical range, making it virtually impossible to predict whether the risk of arterial rupture is high or low. Thus, it is difficult to determine the severity of the disease solely by external clinical examination.

Obviously many more mutations of type III collagen will need to be characterised to establish the relationship between those that cause severe or mild EDS IV and those that cause arterial aneurysms.

The methods used here to map the site of mutation rapidly should lead to quicker analysis of defects in type III collagen and thus determine whether any general rules regarding the phenotype of the disease and the site of the mutation can be made.

This work was supported in part by the EC concerted action on heritable connective tissue disorders 19901992, project leader Dr M Matton. We would like to thank Mrs Olive Cutting for technical assistance in tissue culture. We are also grateful to the Medical Illustration Department in the Clinical Research Centre for production of the figures. 
1 Beighton P. The Ehlers-Danlos syndrome. London: Heinemann Medical Books, 1970.

2 McKusick VA. Heritable disorders of connective tissue. 4th ed. St Louis: Mosby, 1972:292-371.

3 Pope FM, Martin GR, Lichtenstein JR, et al. Patients with Ehlers-Danlos syndrome type IV lack type III collagen. Proc Natl Acad Sci USA 1975;72:1314-6.

4 Byers PM, Holbrook KA, Barsh GS, Smith LT, Bornstein P. Altered secretion of type III procollagen in a form of type IV Ehlers-Danlos syndrome. Lab Invest 1981;44:336-41.

5 Stolle CA, Pyeritz RE, Myers JC, Prockop DJ. Synthesis of an altered type III procollagen in a patient with type IV EhlersDanlos syndrome. F Biol Chem 1985;260:1937-44.

6 Tsipouras P, Byers PH, Schwartz RC, et al. Ehlers-Danlos syndrome type IV: cosegregation of the phenotype to a COL3A1 allele of type III procollagen. Hum Genet 1986;74: 41-6.

7 Nicholls AC, De Paepe A, Narcisi P, et al. Linkage of a polymorphic marker for the type III collagen gene (COL3A I) to atypical autosomal dominant Ehlers-Danlos syndrome type IV in a large Belgian pedigree. Hum Genet 1988;78:276-81.

8 Superti-Furga A, Gugler E, Gitzelmann R, Steinmann B. EhlersDanlos syndrome type IV: a multi exon deletion in one of the two COL $3 \mathrm{Al}$ alleles affecting structure, stability and processing of type III procollagen. 7 Biol Chem 1988;263:6226-32.

9 Superti-Furga A, Steinmann B, Ramirez F, Byers PH. Molecular defects of type III procollagen in Ehlers-Danlos syndrome type IV. Hum Genet 1989;82:104-8.

10 McGookey DJ, Smith ACM, Waldstein G, Byers PH. Mosaicism for a deletion in one of the type III collagen alleles indicates that the deletion occurred after identification of cells for recruitment in different cell lineages early in human development. Abstract 0809. Am f Hum Genet 1989;45(suppl):206A.

11 Kuivaniemi H, Kontusaari S, Tromp G, Shao M, Sabol C, Prockop DJ. Identical $G^{+1}$ to $A$ mutations in three different introns of the type III procollagen gene (COL3A1) produce different patterns of RNA splicing in three variants of Ehlers-Danlos syndrome. An explanation for exon skipping with some mutations and not others. 7 Biol Chem 1990;265: 12067-74.

12 Cole WG, Chido AA, Lamande SR, et al. A base substitution at a splice site in the COL $3 A 1$ gene causes exon skipping and generates abnormal type III procollagen in a patient with Ehlers-Danlos syndrome type IV. F Biol Chem 1990;265: 17070-7.

13 Tromp G, Kuivaniemi H, Shikata H, Prockop DJ. A single base mutation that substitutes serine for glycine 790 of the $\alpha 1$ (III) chain of type III procollagen exposes an arginine and causes Ehlers-Danlos syndrome type IV. F Biol Chem 1989;264: 1349-52.

14 Tromp G, Kuivaniemi H, Stolle C, Pope FM, Prockop DJ. Single base mutation in the type III procollagen gene that converts the codon for glycine 883 to aspartate in a mild variant of Ehlers-Danlos syndrome IV. F Biol Chem 1989;264:19313-7.

15 Bornstein $P$, Traub $W$. The chemistry and biology of collagen. In: Neurath H, Hill RL, eds. The proteins. Vol 4, 3rd ed. New York: Academic Press, 1979:411-632.

16 Byers PH. Inherited disorders of collagen genes structure and expression. Am f Med Genet 1989;34:72-80.

17 Prockop DJ, Constantinou CD, Dombrowski KE, et al. Type I procollagen. The gene protein system that harbours most of the mutations causing osteogenesis imperfecta and probably more common heritable disorders of connective tissue. Am $\mathrm{f}$ Med Genet 1989;34:60-7.

18 Stacey A, Bateman J, Choi T, Mascara T, Cole W, Jaenisch R. Perinatal lethal osteogenesis imperfecta in transgenic mice bearing an engineered mutant pro-(l)(I) collagen gene. Nature 1988;322:131-6.

19 Bonadio J, Byers PH. Subtle structural alterations in the chains of type I procollagen produce osteogenesis imperfecta type II. Nature 1985;316:363-6.

20 Bateman JF, Chan D, Mascara T, Rogers JG, Cole WG. Collagen defects in lethal perinatal osteogenesis imperfecta. Biochem $\mathcal{f}$ 1986;240:699-708.

21 De Paepe A, Nuytinck L, Nicholls AC, Narcisi P, De Roose J, Matton M. Study of a type III collagen protein defect in a patient with ecchymotic EDS: importance of the analysis of non-cutaneous connective tissues. In: Bartsocas C, ed. Proceedings of the VI International Clinical Genetics Seminar: genetics of haematological disorders. Washington DC: Hemisphere (in press).

22 Maniatis T, Fritsch EF, Sambrook J. Molecular cloning: a laboratory manual. Cold Spring Harbor, NY: Cold Spring Harbor Laboratory, 1982.

23 Saiki RK, Scharf S, Faloona F, et al. Enzymatic amplification of B-globin genomic sequences and restriction site analysis for diagnosis of sickle cell anaemia. Science 1985;230:1350-4.

24 Devereaux J, Haeberli $P$, Smithies $O$. A comprehensive set of sequence analysis programs for the VAX. Nucleic Acids Res 1984;12:387-95.

25 Ala-Kokko L, Kontusaari S, Baldwin CT, Kuivaniemi H, Prockop DJ. Structure of cDNA clones coding for the entire preproal(III) chain of human type I procollagen: differences in protein structure from type III procollagen and conservation of codon preferences. Biochem $\mathcal{F}$ 1989;260:509-16.

26 Loidl HR, Brinker JM, May M, et al. Molecular cloning and carboxyl propeptide analysis of human type III procollagen. Nucleic Acids Res 1984;12:9383-94.

27 Roberts RG, Montandon AJ, Bentley DR. Detection of novel genetic markers by mismatch analysis. Nucleic Acids Res 1989;17:5961-71.

28 Southern E. Detection of specific sequences among DNA fragments separated by gel electrophoresis. F Mol Biol 1975;98: 503-8.

29 Wood WI, Gitschier J, Lasky LA, Lawn RM. Base compositionindependent hybridization in tetramethylammonium chloride: a method for oligonucleotide screening of highly complex gene libraries. Proc Natl Acad Sci USA 1985;82:1585-8.

30 Cotton RGH, Rodrigues NR, Campbell RD. Reactivity of cytosine and thymine in single-base pair mismatches with hydroxylamine and osmium tetroxide and its application to the study of mutations. Proc Natl Acad Sci USA 1988;85:4397-401.

31 Kontusaari S, Tromp G, Kuivaniemi H, Romanic A, Prockop DJ. A mutation in the gene for type III procollagen (COL3A1) in a family with aortic aneurysms. F Clin Invest 1990;86: $1465-73$.

32 Lamande SR, Dahl HM, Cole WG, Bateman JF. Characterisation of point mutations in the collagen COL1Al and COL1A2 genes causing lethal perinatal osteogenesis imperfecta. $\mathcal{f}$ Biol Chem 1989;264:15809-12.

33 Sillence DO, Senn AS, Danks DM. Genetic heterogeneity in osteogenesis imperfecta. 7 Med Genet 1979;16:101-16.

34 Sillence DO, Barlow KK, Garber AP, Hall JG, Rimoin DL. Osteogenesis imperfecta type II: delineation of the phenotype with reference to genetic heterogeneity. Am $\mathrm{J}$ Med Genet 1984;17:407-23.

35 Kontusaari S, Tromp G, Kuivaniemi H, Ladda RL, Prockop DJ.

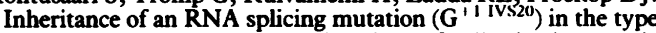
III procollagen gene (COL3A1) in a family having aortic aneurysms and easy bruisability: phenotypic overlap between familial arterial aneurysms and Ehlers-Danlos syndrome type IV. Am J Hum Genet 1990;47:112-20. 